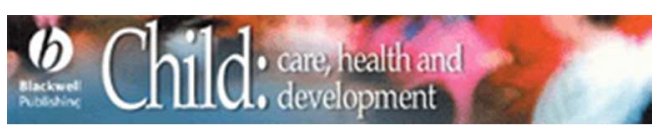

\title{
Factors predicting distress among parents/caregivers of children with neurological disease and home enteral nutrition
}

\begin{tabular}{|r|l|}
\hline Journal: & Child: Care, Health \& Development \\
\hline Manuscript ID: & CCH-2012-0093.R3 \\
\hline Manuscript Type: & Research Article \\
\hline Keywords: & Child Disability, Parenting Stress, Home Care \\
\hline \multicolumn{3}{c}{} \\
\\
\multirow{3}{*}{$\begin{array}{c}\text { SCHOLARONE } \\
\text { Manuscripts }\end{array}$} \\
\end{tabular}




\title{
TITLE:
}

Factors predicting distress among parents/caregivers of children with neurological disease and home enteral nutrition

\begin{abstract}
Background \& aims. Caregivers of children with chronic diseases included in a home enteral nutrition (HEN) program are at risk of experiencing a feeling of burden, high level of anxiety and psychological distress. The aims of this study were: Firstly, to examine the prevalence of symptoms of anxiety-depression in caregivers of children with neurological diseases requiring HEN by gastrostomy tube (GT); secondly, to compare the characteristics of caregivers with high or low risk of exhibiting symptoms of anxiety-depression; thirdly, to investigate possible associations to child disease severity and nutrition support mode.
\end{abstract}

Methods. A cross-sectional observational study was performed in 58 caregivers of children (31 boys, aged 0.3-18 years) with neurological diseases and GT feeding. The characteristics of caregivers with high or low risk of presenting symptoms of anxiety-depression were compared regarding the following variables: socio-demographic characteristics, the primary caregiver's intrapsychic factors, anthropometric parameters of the child, length of HEN, type of nutrients delivered by GT and infusion regime.

Results. All primary caregivers were mothers. Fifty-three percent of them showed high risk of exhibiting symptoms of anxiety-depression. Mothers with high or low risk of presenting symptoms of anxiety-depression were comparable in age and family socioeconomic status. They were also similar in terms of age, anthropometric conditions, and length of HEN in their children. No differences were found between the two groups of mothers according to the level of the child's motor function impairment, type of nutrients delivered by GT and infusion regime. Higher levels of psychological distress and perception of burden overload were found in mothers with high risk of exhibiting symptoms of anxiety-depression.

Conclusions. This study found a high prevalence of symptoms of anxiety-depression, perception of burden overload and psychological distress in caregivers of children with HEN. Thus, greater practical and emotional support is required for these families.

\begin{abstract}
ABBREVIATIONS:
BMI: Body mass index. CI: Confidence interval. GMFCS: Gross motor function classification system. GSI: Global severity index. GT: Gastrostomy tube. HEN: Home enteral nutrition. PD: Psychological distress. PSDI: Positive symptom distress index. SCL-90-R: Symptom Checklist 90 Revised.
\end{abstract}




\section{INTRODUCTION}

Home enteral nutrition (HEN) is a nutritional support technique that achieves improved growth and nutritional status (Kilpinen-Loisa et al. 2009) and reduces half- and long-term morbidity in children with serious chronic diseases (Sleigh \& Brocklehurst 2004). In these children, halfterm malnutrition increases the risk of infection, decreases physical activity and the reaction to external stimuli, and deteriorates the quality of rehabilitation. In the long term, this malnutrition may impede growth, generate orthopedic complications (such as hip dislocation), and disrupt cognitive development, among other effects. The use of HEN contributes to extend the survival rate, particularly of children that are highly dependent and require home support, as is the case of children and adults suffering from serious neurological diseases (Loeser et al. 2003). Furthermore, HEN may also enhance their quality of life (Daveluy et al. 2005) while reducing healthcare costs (Gómez-López et al. 2010).

However, undertaking HEN, especially in the context of gastrostomy tube (GT) placement, constitutes a stressful situation both for the children and for their parents/caregivers (Mahantet al. 2011, Petersen et al. 2006). Primary caregivers must be motivated to assume this treatment, because it requires specific training in the management of the child's particular disease, potential mechanical and infectious complications, metabolic issues, psychosocial problems and the devices used (Murphy et al. 2007; Sleigh \& Brocklehurst 2004). This heavy emotional burden may adversely affect the physical and psychological health of primary caregivers (Petersen et al. 2006), especially the mother, who tends to assume the main role in the child's care (Heyman et al. 2004). In an earlier study by our group, caregivers of children with chronic diseases included in a HEN program were found to experience burden, high levels of anxiety and psychological distress (Calderón et al. 2011). In this study, the focus was set on the identification of the specific factors that are linked to stress (assessed by symptom checklist 90 revised) in caregivers of children with neurological diseases. In particular, the aims of this study were: Firstly, to examine the prevalence of symptoms of anxiety-depression in caregivers of children with neurological diseases requiring HEN by gastrostomy tube (GT); secondly, to compare the socio-demographic and intrapsychic characteristics of caregivers with high or low risk of exhibiting symptoms of anxiety-depression; thirdly, to determine its association with child disease severity and nutrition support mode (type of nutrients and infusion regime). 


\section{METHODS}

Design

A cross-sectional observational study was carried out between September 2008 and September 2009 at the Pediatric Gastroenterology and Nutrition Units of two Spanish public hospitals. The sample comprised voluntary caregivers of children in whom GT feeding had been indicated. The study protocol was approved by the Ethics Committee of each hospital in accordance with the Declaration of Helsinki of 1964, revised in Seoul in 2008. Written parental informed consent was obtained.

\section{Participants}

The participants of this study were caregivers of children presenting neurological pathology as the primary or secondary diagnosis. Sixty-one caregivers were included, 3 of whom declined to participate; thus, the final sample comprised 58 participants. Table 1 summarizes the characteristics of the children, primary caregivers, and family's socioeconomic status. This last parameter was calculated using the Hollingshead family's socioeconomic status scale (Hollingshead. 1975).

\section{Child variables}

In order to assess nutritional status, the weight and height of each child were measured and recorded using a standardized technique with age-appropriate material: clinical scale or Seca ${ }^{\circledR}$ baby scale (models 755/334) and infant measuring table or Holtain ${ }^{\circledR}$ stadiometer (Harpenden models). Other analyzed parameters included body mass index (BMI) [calculated as weight (kg) divided by height squared $\left(\mathrm{m}^{2}\right)$ ], and weight/height ratio, for children under the age of five. Weight and height measurements, weight/height ratio and BMI were converted to z-scores for age and sex using WHO growth standards (De Onis et al. 2006) [WHO Anthro Software (version 3.2.2, June, 2010)] for children under five and WHO AnthroPlus Software (version 3.2.2, June, 2010) for children over five. For children over 10, the WHO standards lack z scores for weight/age. Moreover, the BMI z-score for classifying the nutritional status of some teenagers whose height could not be accurately measured due to deformities could not be calculated.

- A gross motor function classification system (GMFCS) was applied to categorize children with cerebral palsy based on self-initiated motor function (Palisano et al. 2006). Standardized, chronology-based descriptions of motor abilities were used to rate the child's abilities and limitations in gross motor function. Children were categorized into five functional levels where level $\mathrm{I}$ is equivalent to a higher voluntary motor control and level $\mathrm{V}$ to greater functional impairment. A dichotomous variable was created to classify the children into two groups: Those 
with moderate limitations in motor function (levels I-III) and those with severe limitations (levels IV-V). The GMFCS has proven to be a valid, reliable, and stable classification system over time and in multiple studies (Gillick \& Koppes 2010; Matsumoto et al. 2011).

\section{- Nutritional support mode}

In order to describe the nutritional support mode, the type of nutrients delivered by GT and the particular infusion regime were analyzed. Regarding the type of nutrients, the distinction between homemade meals and enteral formulas was made. Children were classified in the group of homemade meals when more than $60 \%$ of their intake was composed of natural food. With respect to infusion regime, the distinction was made between intermittent bolus feeding and cyclic or continuous infusion. Syringes were used when intermittent bolus feeding was administered, and pumps when cyclic or continuous infusions were indicated. The pumps used were compact and portable (Abbott Companion Clear Star ${ }^{\circledR}$ and Nestlé Nutrition CompatGoß). Regarding tube type, a PEG tube (percutaneous endoscopic gastrostomy) was implemented in 48 children, a ball button was placed in 9 cases following surgical gastrostomy, and a gastrojejunal device was only used in one child.

\section{Caregiver psychological assessment}

- Symptom Checklist 90 Revised. To measure participants' psychological distress (PD), the Spanish version (Gónzalez de Rivera et al. 2002) of the SCL-90-R (Derogatis, 1994) was used. This inventory includes 90 symptoms to assess the degree of discomfort on a Likert-type fivepoint scale ranging from 1 (total absence of symptom) to 5 (full presence of symptom). The scale provides nine groups of symptoms: somatization disorder, obsessive-compulsive disorder, interpersonal sensitivity, depression, anxiety, hostility, phobic anxiety, paranoid ideation and psychoticism. A global severity index (GSI) and a positive symptom distress index (PSDI) were calculated. The test-retest reliability ranged from 0.78 to 0.90 . Cronbach's alpha ranged from 0.81 to 0.90 .

- Caregiver Burden Inventory (Zarit). The Zarit scale (Hanzawaet al. 2008), which was designed to assess the feeling of burden experienced by caregivers of patients with a high degree of dependence, was used. This scale was chosen as a common tool to evaluate the intensity of the caregiver's feeling of burden (Black et al. 2009). It consists of 22 items that assess the negative impact on certain everyday tasks associated with care-giving, the effects on the caregiver's expectations and beliefs, and the relationship between caregiver and patient. The caregiver was given a Likert-type scale of five frequency values ranging from 0 (not present) to 4 (always present). The scores obtained for each item were added up, and the degree of burden on the caregiver was given by the total sum. The possible results range from 0 to 88 points. Psychometric properties were satisfactory with Cronbach's alpha of 0.91 and good test-retest reliability of 0.91 . In this study, we did not establish cut-offs; instead correlations between these scores and the other variables were analyzed. 


\section{- Evaluation criteria for symptoms of anxiety-depression}

Initial evaluation of all subjects was carried out via the individualized application of the two aforementioned tools, SCL-90-R and Zarit. The selection criterion proposed by Derogatis was used to determine the condition of the caregivers with high or low risk of presenting symptoms of anxiety-depression (Derogatis, 1994). Caregivers whose scores corresponded to the $90^{\text {th }}$ percentile or above on the anxiety and/or depression SCL-90-R subscales were considered to present high risk to exhibitsymptoms of anxiety-depression; caregivers who scored within the normal range were considered symptom-free or presenting low risk to exhibit symptoms. Globally, results were stratified according to age and sex.

\section{Data analysis}

The characteristics of caregivers with high or low risk of exhibiting symptoms of anxietydepression were described, in the case of quantitative variables, with means and standard deviations; frequencies and percentages were used for qualitative variables. In order to analyze the differences between both groups, the Student's $t$ test for Equality of Means was applied to the following variables: socio-demographic characteristics (age and family socioeconomic status), primary caregiver's intrapsychic factors (somatization, obsession-compulsion, interpersonal sensitivity, hostility, phobic anxiety, psychotic behavior, paranoid ideation, GSI, PSDI and caregiver burden) and anthropometric parameters. Unifactorial logistic regressions were used to investigate the relationship between high/low risk of presenting anxiety/depression symptoms and the following variables: child disease severity (motor function impairment), type of nutrients, infusion regime, child's age and length of HEN. The Statistical Package for Social Sciences (SPSS) version 16.0 was used for data processing. In all cases, statistical significance was set at $\mathrm{p}<0.05$.

\section{RESULTS}

\section{Socio-demographic variables of primary caregivers and children}

The characteristics of the studied children and their caregivers are displayed on Table 1. Most children $(70.7 \%)$ presented a primary neurological pathology. All primary caregivers were mothers. The application of Student's $t$ test to maternal age, family socioeconomic status and anthropometric evaluation in relation to the low or high risk of presenting symptoms of anxietydepression (Table 2) found no statistically significant differences. Mothers with high or low risk of exhibiting symptoms of anxiety-depression were comparable regarding age and family socioeconomic status. They were also similar in terms of anthropometric conditions.

\section{Child disease severity and nutrition support mode}

Table 3 shows the results for the odds-ratio analysis to describe the association between motor function impairment levels IV-V, type of nutrients delivered by GT and means of delivery, and 
presence of anxiety-depression symptoms in mothers. No differences were found between the two groups of mothers according to the level of the child's motor function impairment $\left(\chi^{2}\right.$ : 0.917, p: 0.338, OR: 1.909, IC95\%: $0.508-7.172$ ) and type of nutrients delivered by GT (homemade meals vs enteral formulas) $\left(\chi^{2}: 1.693\right.$, p: 0.193, OR: 0.470, IC95\%: $\left.0.151-1.465\right)$. The most common infusion regime was intermittent bolus feeding (35 cases), compared to continuous or cyclic feeding (23 cases). Comparable levels of caregiver anxiety-depression were found with both regimes, $\left(\chi^{2}: 0.350, \mathrm{p}: 0.554\right.$, OR: 0.726 IC95\%: $\left.0.252-2.092\right)$, no statistically significant differences. Similarly, no statistically significant differences were detected in when comparing children's age $\left(\chi^{2}: 0.018, \mathrm{p}: 0.893\right.$, OR: 0.917, OR95\%: $\left.0.257-2.267\right)$ and length of HEN $\left(\chi^{2}: 0.158\right.$, p: 0.691, OR: 1.021, OR95\%: 0.920-1.14) with respect to mothers high or low risk of presenting symptoms of anxiety-depression.

\section{Intrapsychic factors of primary caregivers}

Mothers with high risk of exhibiting symptoms of anxiety-depression obtained significantly higher scores in five of the nine test scales of the SCL-90-R (Table 4): somatic complaints $(\mathrm{p}=0.001)$, obsessive-compulsive complaints $(\mathrm{p}=0.006)$, phobic anxiety $(\mathrm{p}=0.001)$, hostility $(\mathrm{p}=0.001)$, Global Severity Index $(\mathrm{p}=0.001)$, and Positive Symptom Distress Index $(\mathrm{p}=0.001)$. Overall, greater psychological distress was found among mothers with high risk of presentingsymptoms of anxiety-depression.

In the scale for the perception of burden overload (Zarit), mothers who suffered high risk of presenting symptoms of anxiety-depression scored higher $(\mathrm{p}=0.008)$ than those who did not have symptoms of anxiety-depression.

\section{DISCUSSION}

The results of this study confirm that caregivers of children with underlying neurological diseases and HEN support by GT are at high risk of psychological distress. Considering the sample globally, 53\% of mothers presented high risk of exhibiting symptoms of anxietydepression. These findings agree with previous studies on the emotional impact of a child's severe illness on care-providing mothers (Calderón et al. 2011; Murphy et al. 2007; Davis et al. 2010), probably due to stress associated with daily life (i.e., time dedicated to care, caregiving itself, child feeding) (Rentinck et al. 2009). Some authors have indicated that this type of stress is the greatest predictor for the appearance of emotional and health problems, especially among caregivers of children suffering from progressive illnesses (Brown et al. 2008); and is strongly supported in the literature that mother of children with chronic illness, experience higher rates of depression, burn-out and anxiety (Coffey 2006; Twe et al. 2010; Wiedebusch et al. 2010). 
The results of this study showed that the mothers who obtained higher scores for symptoms of anxiety and/or depression also scored higher for somatic and obsessive-compulsive complaints, phobic anxiety, hostility, psychological distress, and positive symptomatic unease. That is, they showed greater psychosomatic symptomatology, greater presence of unwanted obsessive thoughts, more negative affectivity (such as anger and irritability), and greater disproportionate fear in relation to stimuli as well as more symptoms producing uneasiness. This conclusion agrees with other studies performed on mothers of children with cerebral palsy, where caregiving mothers showed significantly higher levels of emotional uneasiness in comparison to control mothers with healthy children (Lim \& Zebrack 2004, White-Koning et al. 2007).

The two groups of mothers in this study were comparable in terms of age and FSS. Participants' educational level and unemployment rate were higher than that of the average Spanish female population. (National Institute of Statistical, 2004). These results lead us to hypothesize that women who are responsible for the care of highly dependent neurological disease children suffer not only emotional repercussions, but also social, personal, and work-related consequences (Beneken Genaamd Kolmer et al. 2008). Future studies are necessary to further investigate these aspects.

Regarding children's anthropometric parameters, no significant differences were found between the two groups. Hence, it seems the child's nutritional status was not the determining factor of stress level in caregivers. This finding may be explained by mothers' perception that their children are already receiving adequate nutritional support. Besides, GT feeding eases their daily life by decreasing necessary feeding times and feeding-derived stress (Sullivan et al. 2004).

Regarding the level of the child's motor impairment, no differences were found between the two groups of mothers, although it would also be reasonable. This could be a consequence of the sample size, too small for differences to be noted. However, it is also suggested that other factors such as communication difficulties or the child's emotional characteristics are more related to the caregiver's stress. More research is needed in these grounds to make a reach a decision in this matter. Other studies have reported an association between stress levels parents of children with GT feeding and children's illness/disability due they care demanding (Pedersen et al. 2004).

Concerning the type of nutrients, the authors' clinical experience indicates that many mothers, especially those having very young children, have a preference for food that is liquidized at home. This option enables them to quantitatively feed their children as much as they would a "normal child". Routine practice has not revealed significant clinical or biochemical differences in children nutritional status with respect to the type of nutritional support (unpublished data). The initial hypothesis was based in the fact that mothers that relied on homemade meals would surely present a higher degree of anxiety/depression due to the greater burden derived from the 
necessary shopping, cooking, and liquidizing required to avoid GT blockage. It was also considered that this increased workload, close to being a full-time job, would also result in social isolation and an additional economic burden (bearing in mind that, in our country, HEN formulas are thoroughly financed by the National Health Service). However, the present study revealed no significant differences in the probability of presenting anxiety-depression symptoms between mothers who fed their children with homemade food and those who did not. Thus, our recommendation is that, in the near future, relying on homemade meals for the child's feeding is a decision that should be taken by the patient's mother, unless it represents a risk for the child's nutritional status. Future studies are still needed to examine these aspects more deeply.

In analyzing other factors that might contribute to increasing the level of maternal anxietydepression, such as the infusion regime (intermittent bolus feeding versus continuous or cyclic infusion), children's age and length of HEN no significant differences were found between the two mother groups.

In agreement with other authors (Grootenhuis et al. 2009), the results of the present study emphasize the importance of psychological well-being of mothers of children with neurological diseases that require prolonged HEN by GT. The group of mothers with anxiety-depression symptoms showed increased scores on the subscales that measure psychological distress. Hence, not only is this a population that is vulnerable to developing anxiety and/or depression; other psychopathological domains may become involved as well.

Regardless the importance of this study's findings, several limitations must be acknowledged: Firstly, the sample comprised mothers only; hence, results may not be applicable to fathers or other caregiving family members. Nevertheless, it is a fact that mothers are usually the primary caregivers of children with GT feeding. Secondly, the transversal nature of this study limits the ability to withdraw causational or directional conclusions. Thirdly, since the sample is comprised by mothers of children suffering from neurological diseases, results may not be readily applicable to mothers of children with other underlying diseases. Finally, the relatively small sample size imposes an overall limitation to result extrapolation.

Despite these limitations, the authors believe that results powerfully illustrate two key points: 1) The magnitude of the psychological impact of caregiving on parents of children with neurologic disabilities who require GT feeding, and 2) The importance of integrating the child's family into routine paediatric practice. It is absolutely essential that the mothers of this particular type of children undergo continued psychological evaluation, and, if needed, multidisciplinary support must be provided in order to mitigate the repercussions of caregiving. If this psychological burden is ignored and untreated, there is a high risk of adverse effects on mothers' personal, social and professional lives, and in their global quality of life (Fortin et al. 2004). Indeed, this study provides valuable information about an understudied issue in a specific context. Not only does it intend to estimate the prevalence of psychological symptoms in caregivers, but it also 
puts forward specific variables that may potentially act as risk factors. Future research should further investigate possible factors of personal and family protection, such as family background, economic and health support, and other variables linked to the health and psychological well-being of parents of children with HEN.

In conclusion, taking into consideration the limitations of the study, we found a high prevalence of anxiety-depression symptoms and psychological distress in caregivers of children with HEN. Increased efforts should be aimed at improving practical and emotional support for these families. 


\section{KEY MESSAGES}

- A high percentage (53\%) of caregivers of children with neurological diseases and home enteral nutrition support showed a high risk of presenting anxiety-depression symptoms.

- Higher levels of psychological distress and perception of burden overload were found in mothers with high risk of presenting anxiety-depression symptoms.

- These families are in the need for greater practical and emotional support. 


\section{REFERENCES}

Beneken Genaamd Kolmer, D.M. Tellings, A. Gelissen, J. Garretsen, H. \& Bongers, I. (2008) Ranked motives of long-term care providing family caregivers. Scandinavian journal of caring sciences, 22, 29-39.

Black, B.P. Holditch-Davis, D. \& Miles, M.S. (2009) Life course theory as a framework to examine becoming a mother of a medically fragile preterm infant. Research in nursing \& health, 32, 38-49.

Brown, R.T. Wiener, L. Kupst, M.J. Brennan, T. Behrman, R. Compas, B.E. David Elkin, T. Fairclough, D.L. Friebert, S. Katz, E. Kazak, A.E. Madan-Swain, A. Mansfield, N. Mullins, L.L. Noll, R. Patenaude, A.F. Phipps, S. Sahler, O.J. Sourkes, B. \& Zeltzer, L. (2008) Single parents of children with chronic illness: an understudied phenomenon. Journal of pediatric psychology, 33, 408-421.

Calderón, C. Gómez-López, L. Martínez-Costa, C. Borraz, S. Moreno-Villares, J.M. \& PedrónGiner, C. (2011) Feeling of burden, psychological distress, and anxiety among primary caregivers of children with home enteral nutrition. Journal of pediatric psychology, 36(2), 188195.

Coffey JS. (2006) Parenting a child with chronic illness: a metasynthesis. Pediatric nursing, 32(1), 51-59.

Daveluy, W. Guimber, D. Mention, K. Lescut, D. Michaud, L. Turck, D. \& Gottrand, F. (2005) Home enteral nutrition in children: an 11-year experience with 416 patients. Clinical nutrition, 24(1), 48-54.

Davis, E. Shelly, A. Waters, E. Boyd, R. Cook, K. Davern, M. \& Reddihough, D. (2010) The impact of caring for a child with cerebral palsy: quality of life for mothers and fathers. Child: care, health and development, 36, 63-73.

De Onis, M. Garza, C. Onyango, A.W. \& Martorell, R. WHO.(2006) Child Growth Standards. Acta Paediatrica, 450, S1-S104. http://www.who.int/childgrowth/standards/en/index.html and http://www.who.int/growthref/en// (accessed May 12, 2010).

Derogatis, L.R. (1994) SCL-90-R. Administration, Scoring and Procedures Manual (Third Edition). Minneapolis: National Computer Systems.

Fortin, M. Lapointe, L. Hudon, C. Vanasse, A. Ntetu, A.L. \& Maltais, D. (2004) Multimorbidity and quality of life in primary care: a systematic review. Health and quality of life outcomes, 2 , 
51. doi:10.1186/1477-7525-2-51.

Gillick, B.T. \& Koppes, A. (2010) Gross motor outcomes in children with hemiparesis involved in a modified constraint-induced therapy program. Journal of Pediatric Rehabilitation Medicine, 3(3): 171-175.

Gómez-López, L. Martínez-Costa, C. Pedrón-Giner, C. Calderón-Garrido, C. Navas López, V.M. Martínez Zazo, A. \& Moreno Villares, JM. (2010) Current status of pediatric home enteral nutrition in Spain: the importance of the NEPAD register. Nutrición hospitalaria, 25(5), 810813.

González de Rivera, J.L. De las Cuevas, C. Rodriguez, M. \& Rodriguez, F. (2002) Cuestionario de 90 sintomas SCL-90-R de Derogatis, L. Spanish version. Madrid: TEA Ediciones.

Grootenhuis, M.A. \& Bronner, M.B. (2009) Paediatric illness! Family matters. Acta paediatrica, 98, 940-941.

Hanzawa, S. Tanaka, G. Inadomi, H. Urata, M. \& Ohta, Y. (2008) Burden and coping strategies in mothers of patients with schizophrenia in Japan. Psychiatry and clinical neurosciences, 62, 256-263.

Heyman, M.B. Harmatz, P. Acree, M. Wilson, L. Moskowitz, J.T. Ferrando, S. \& Folkman, S.(2004) Economic and psychologic costs for maternal caregivers of gastrostomy-dependent children. The Journal of pediatrics, 145, 511-516.

Hollingshead, A.B. (1975) Four factor index of social status. New Haven (Connecticut). Department of Sociology, Yale University.

Instituto Nacional de Estadística (2009) Mujeres y hombres en España 2009. Madrid: INE. http://www.ine.es/ (accessed January 12, 2011).

Kilpinen-Loisa, P. Pihko, H. Vesander, U. Paganus, A. Ritanen, U. \& Mäkitie, O. (2009) Insufficient energy and nutrient intake in children with motor disability. Acta paediatrica, 98, 1329-1333.

Lim, J.W. \& Zebrack, B. (2004) Caring for family members with chronic physical illness: a critical review of caregiver literature. Health and quality of life outcomes, 2 , 50.doi:10.1186/1477-7525-2-50.

Loeser, C. von Herz, U. Küchler, T. Rzehak, P. \& Müller, M.J. (2003) Quality of life and 
nutritional state in patients on home enteral tube feeding. Nutrition, 19, 605-611.

Mahant, S. Jovcevska, V. \& Cohen, E. (2011) Decision-making around gastrostomy-feeding in children with neurologic disabilities. Pediatrics, 127(6), e1471-1481.

Matsumoto, H., Clayton-Krasinski, D,A., Klinge, S.A., Gómez, J.A., Booker, W.A., Hyman, J.E., Roye, D.P. \&Vitale, M.G. (2011) Development and initial validation of the assessment of caregiver experience with neuromuscular disease. Journal of Pediatric Orthopedic, 31(3): 284292.

Murphy, N.A. Christian, B. Caplin, D.A. \& Young, P.C. (2007) The health of caregivers for children with disabilities: caregiver perspectives. Child: care, health and development, 33(2), 180-187.

Palisano, R.J. Cameron, D. Rosenbaum, P.L. Walter, S.D. \& Russell, D. (2006) Stability of the gross motor function classification system. Developmental medicine and child neurology, $\mathbf{4 8 ,}$ 424-428.

Pedersen, S.D. Parsons, H.G. \& Dewey, D. (2004) Stress levels experienced by the parents of enterally fed children. Child: care, health and development, 30(5), 507-513.

Petersen, M.C. Kedia, S. Davis, P. Newman, L. \& Temple, C. (2006) Eating and feeding are not the same: caregivers' perceptions of gastrostomy feeding for children with cerebral palsy. Developmental medicine and child neurology, 48, 713-717.

Rentinck, I. Ketelaar, M. Jongmans, M. Lindeman, E. \& Gorter, J.W. (2009) Parental reactions following the diagnosis of cerebral palsy in their young child. Journal of pediatric psychology, 34, 671-676.

Sleigh, G. \& Brocklehurst, P. (2004) Gastrostomy feeding in cerebral palsy: a systematic review. Archives of disease in childhood, 89, 534-539.

Sullivan, P.B. Juszczak, E. Bachlet, A.M. Thomas, A.G. Lambert, B. Vernon-Roberts, A. Grant, H.W. Eltumi, M. Alder, N. \& Jenkinson, C. (2004) Impact of gastrostomy tube feeding on the quality of life of careers of children with cerebral palsy. Developmental medicine and child neurology, 46, 796-800.

Tew K, Landreth GL, Joiner KD, et al. (2010) Filial therapy with parents of chronically ill children. In: Baggerly JN, Ray DC, Bratton SC, eds. Child-centered play therapy research: the evidence base for effective practice. Hoboken, NJ: Wiley, 295-309. 


\begin{abstract}
White-Koning, M. Arnaud, C. Dickinson, H.O. Thyen, U. Beckung, E. Fauconnier, J. McManus, V. Michelsen, S.I. Parkes, J. Parkinson, K. Schirripa, G. \&Colver, A. (2007) Determinants of child-parent agreement in quality-of-life reports: a European study of children with cerebral palsy. Pediatrics, 120, e804-814.
\end{abstract}

Wiedebusch S, Konrad M, Foppe H, et al. (2010) Health-related quality of life, psychosocial strains, and coping in parents of children with chronic renal failure. Pediatric nephrology, 25(8), $1477-1485$. 
Table 1

Characteristics of children and their caregivers $(N=58)$

\begin{tabular}{|c|c|c|c|c|c|}
\hline Children & $\mathbf{n}$ & $\%$ & Mean & SD & Range \\
\hline \multicolumn{6}{|l|}{ Age (years) } \\
\hline$<2$ years & 12 & 20.7 & 1.29 & 0.56 & $0.3-2.0$ \\
\hline$\geq 2.1$ years & 46 & 79.3 & 9.19 & 4.8 & $2.1-18$ \\
\hline \multicolumn{6}{|l|}{ Gender: } \\
\hline Boys & 31 & 53.4 & & & \\
\hline Girls & 27 & 46.6 & & & \\
\hline Length of home enteral nutrition (years) & & & 6.93 & 4.98 & $0.7-17$ \\
\hline \multicolumn{6}{|l|}{ Main diagnosis } \\
\hline Neurological disease $^{\mathrm{a}}$ & & 70.7 & & & \\
\hline Secondary neurological disease ${ }^{\mathrm{b}}$ & & 29.3 & & & \\
\hline \multicolumn{6}{|l|}{ Educational level } \\
\hline Elementary school & & 5.9 & & & \\
\hline High school & & 3.9 & & & \\
\hline Special education & & 54.9 & & & \\
\hline No schooling & & 35.3 & & & \\
\hline \multicolumn{2}{|l|}{ Primary caregiver } & $\%$ & Mean & SD & Range \\
\hline \multicolumn{2}{|l|}{ Maternal age (years) } & & 38.22 & 6.28 & $24-54$ \\
\hline \multicolumn{2}{|l|}{ Higher education } & 32.1 & & & \\
\hline \multicolumn{2}{|l|}{ Not working } & 46.4 & & & \\
\hline \multicolumn{2}{|l|}{ Working part-time } & 26.8 & & & \\
\hline \multicolumn{2}{|l|}{ Working full-time } & 26.8 & & & \\
\hline \multicolumn{2}{|l|}{ Family } & $\%$ & Mean & SD & Range \\
\hline \multicolumn{3}{|l|}{ Familial socioeconomic status } & 33.82 & 13.56 & $11-58.5$ \\
\hline \multicolumn{2}{|l|}{ Caregivers living with a partner } & 86.2 & & & \\
\hline \multicolumn{2}{|l|}{ Only one child in the family } & 54.9 & & & \\
\hline \multicolumn{2}{|l|}{ Two children in the family } & 37.3 & & & \\
\hline \multicolumn{2}{|l|}{ Three or more children in the family } & 7.9 & & & \\
\hline \multicolumn{6}{|l|}{ Residency } \\
\hline \multicolumn{2}{|l|}{ Large city } & 29.6 & & & \\
\hline \multicolumn{2}{|l|}{ Outskirts of a large city } & 11.1 & & & \\
\hline \multicolumn{2}{|l|}{ Small city } & 33.2 & & & \\
\hline \multicolumn{2}{|l|}{ Town } & 26.1 & & & \\
\hline \multicolumn{6}{|c|}{$\begin{array}{l}{ }^{a} \text { Cerebral palsy }(n=16) \text {, sequelae of infections or trauma to the central nervous system }(C N S)(n=3) \text {, CNS } \\
\text { malformations }(n=3) \text {, neuromuscular diseases }(n=3) \text {, neurodegenerative diseases }(n=3) \text {, chromosomopathies }(n= \\
\text { 3), epileptic encephalopathies }(n=3) \text {, other diagnoses }(n=7) \text {. } \\
\text { b Metabolic disease }(n=6) \text {, cardio-respiratory disease }(n=4) \text {, oncologic disease }(n=4) \text {, swallowing disorder }(n= \\
\text { 2), digestive disorder }(n=1) \text {. }\end{array}$} \\
\hline
\end{tabular}




\section{Table 2}

\section{Comparison between mothers with low or high risk of presenting symptoms of anxiety-} depression regarding socio-demographic variables and child anthropometry: Mean and SD, t-test for Equality of Means, and $95 \%$ CI.

\begin{tabular}{|c|c|c|c|c|c|c|c|c|}
\hline \multirow[t]{2}{*}{ Variables } & \multicolumn{2}{|c|}{$\begin{array}{l}\text { Mothers with low } \\
\text { risk of presenting } \\
\text { symptoms of } \\
\text { anxiety-depression } \\
\qquad(\mathrm{n}=27)\end{array}$} & \multicolumn{2}{|c|}{$\begin{array}{l}\text { Mothers with high } \\
\text { risk of presenting } \\
\text { symptoms of } \\
\text { anxiety-depression } \\
\qquad(\mathrm{n}=\mathbf{3 1})\end{array}$} & \multicolumn{2}{|c|}{$\begin{array}{l}\text { t-test for Equality } \\
\text { of Means }{ }^{\mathrm{a}}\end{array}$} & \multicolumn{2}{|c|}{$\begin{array}{l}95 \% \text { CI of the } \\
\text { difference. }\end{array}$} \\
\hline & Mean & SD & Mean & SD & $t$ & Sig & Lower & Upper \\
\hline \multicolumn{9}{|l|}{$\begin{array}{c}\text { Socio-demographic } \\
\text { variables }\end{array}$} \\
\hline $\begin{array}{l}\text { Primary } \\
\text { caregiver } \\
\text { age (years) }\end{array}$ & 38.04 & 5.66 & 38.35 & 6.81 & -0.18 & 0.857 & -3.77 & 3.14 \\
\hline FSS & 34.70 & 15.28 & 33.14 & 12.28 & 0.42 & 0.676 & -5.88 & 9.01 \\
\hline \multicolumn{9}{|l|}{$\begin{array}{c}\text { Child } \\
\text { anthropometry } \\
\text { (z-score })\end{array}$} \\
\hline Weight/age ${ }^{\mathbf{b}}$ & -3.01 & 1.90 & -2.29 & 1.79 & -1.29 & 0.204 & -1.84 & 0.40 \\
\hline Height/age ${ }^{\mathbf{c}}$ & -2.64 & 1.87 & -2.37 & 1.43 & -0.58 & 0.559 & -1.21 & 0.66 \\
\hline Weight/height ${ }^{\text {d }}$ & -2.03 & 2.10 & -1.14 & 1.98 & -1.31 & 0.200 & -2.35 & 0.51 \\
\hline BMI/age ${ }^{e}$ & -1.81 & 1.93 & -1.50 & 2.15 & -0.53 & 0.594 & -1.48 & 0.86 \\
\hline \multicolumn{9}{|c|}{ 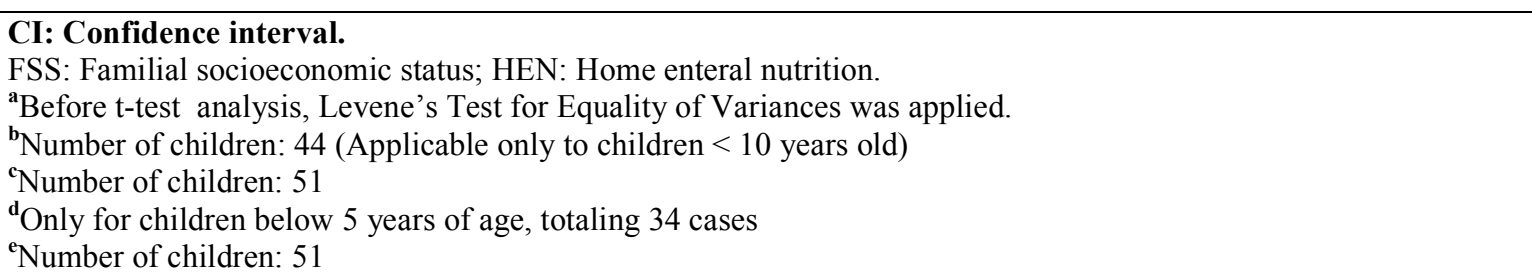 } \\
\hline
\end{tabular}

Child: Care, Health and Development 
Table 3.

Unifactorial logistic regressions between high/low risk of presenting anxiety/depression symptoms in mother and the following variables: motor function impairment, type of nutrients, infusion regime, child age and lenght of HEN.

\begin{tabular}{|c|c|c|c|c|c|}
\hline Variables in the Equation & Wald & sig & $\begin{array}{l}\text { Odds } \\
\text { ratio }\end{array}$ & $\begin{array}{c}\text { OR } \\
\text { lower } \\
95 \%\end{array}$ & $\begin{array}{c}\text { OR } \\
\text { upper } \\
95 \%\end{array}$ \\
\hline 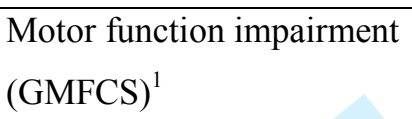 & 0.917 & 0.338 & 1.909 & 0.508 & 7.172 \\
\hline Type of nutrients ${ }^{2}$ & 1.693 & 0.193 & 0.470 & 0.151 & 1.465 \\
\hline Infusion regime $^{3}$ & 0.350 & 0.554 & 0.726 & 0.252 & 2.292 \\
\hline Child age (years) ${ }^{4}$ & 0.018 & 0.893 & 0.917 & 0.257 & 3.267 \\
\hline Length of HEN (years) & 0.158 & 0.691 & 1.021 & 0.920 & 1.134 \\
\hline $\begin{array}{l}\text { Dependent variable encodi } \\
\text { anxiety-depression and } 0 \mathrm{mc} \\
{ }^{1} \text { Motor function impairme } \\
{ }^{2} \text { Type of nutrients is coded } \\
{ }^{3} \text { Infusion regime is coded } 0 \\
{ }^{4} \text { Child age is coded } 0,1(<2\end{array}$ & $\begin{array}{l}1 \text { moth } \\
\text { rs with } 1 \\
\text { GMFC } \\
\text { (Formu } \\
\text { Continu } \\
\text { ars or } \geq\end{array}$ & $\begin{array}{l}\text { with hig } \\
\text { risk. } \\
\text { coded } \\
\text { s Home } \\
\text { or cycli }\end{array}$ & $\begin{array}{l}\text { k of pre } \\
\text { (Level I } \\
\text { le meals } \\
\text { Intermi }\end{array}$ & $\begin{array}{l}\text { ting sym } \\
\text { vs Leve } \\
\text { th bolus) }\end{array}$ & Vms of \\
\hline
\end{tabular}


Table 4.

Comparison between mothers with low or high risk of presenting symptoms of anxiety-depression regarding psychological variables (SCL-90-R)

\begin{tabular}{|c|c|c|c|c|c|c|c|c|}
\hline & \multicolumn{2}{|c|}{$\begin{array}{l}\text { Mothers with low risk of } \\
\text { presenting symptoms of } \\
\text { anxiety-depression } \\
(\mathrm{n}=27)\end{array}$} & \multicolumn{2}{|c|}{$\begin{array}{l}\text { Mothers with high risk } \\
\text { of presenting symptoms } \\
\text { of anxiety-depression (n } \\
=31 \text { ) }\end{array}$} & \multicolumn{2}{|c|}{$\begin{array}{c}\text { t-test for Equality of } \\
\text { Means }^{\text {a }}\end{array}$} & \multicolumn{2}{|c|}{$\begin{array}{l}\text { 95\% Confidence } \\
\text { Interval of the } \\
\text { Difference }\end{array}$} \\
\hline & Mean & SD & Mean & SD & $t$ & Sig & Lower & Upper \\
\hline \multicolumn{9}{|l|}{ SCL-90-R } \\
\hline Somatic & 58.74 & 24.01 & 80.81 & 19.17 & -3.88 & 0.001 & -33.43 & -10.70 \\
\hline Obsessive-compulsive & 49.37 & 32.50 & 71.90 & 27.02 & -2.88 & 0.006 & -38.44 & -6.62 \\
\hline Phobic anxiety & 35.07 & 20.22 & 60.48 & 27.13 & -3.99 & 0.001 & -38.15 & -12.66 \\
\hline Hostility & 41.78 & 29.11 & 67.90 & 28.11 & -3.47 & 0.001 & -41.19 & -11.05 \\
\hline Interpersonal sensitivity & 37.30 & 24.83 & 40.13 & 27.11 & -0.41 & 0.681 & -16.58 & 10.92 \\
\hline Psychotic & 32.22 & 25.20 & 44.16 & 26.30 & -1.75 & 0.084 & -25.54 & 1.66 \\
\hline Paranoid ideation & 32.96 & 23.38 & 40.48 & 27.79 & -1.21 & 0.233 & -20.01 & 4.97 \\
\hline GSI & 54.48 & 23.64 & 77.97 & 19.97 & -4.10 & 0.001 & -34.95 & -12.01 \\
\hline PSDI & 56.59 & 21.59 & 78.65 & 20.24 & -4.01 & 0.001 & -33.06 & -11.04 \\
\hline \multicolumn{9}{|l|}{ Zarit } \\
\hline Caregiver overload & 51.41 & 19.98 & 65.07 & 17.22 & -2.77 & 0.008 & -23.53 & -3.78 \\
\hline
\end{tabular}

